\title{
Interleukin-27 re-educates intratumoral myeloid cells and down-regulates stemness genes in non-small cell lung cancer
}

\author{
Irma Airoldi ${ }^{1, *}$, Maria Grazia Tupone ${ }^{2,3, *}$, Silvia Esposito ${ }^{2,3}$, Marco V. Russo $^{2,3}$, Giulia \\ Barbarito ${ }^{1}$, Giuseppe Cipollone ${ }^{4,5}$, Emma Di Carlo',3 \\ 1'Laboratory of Oncology, Istituto "Giannina Gaslini", Genova 16147, Italy \\ ${ }^{2}$ Anatomic Pathology and Molecular Medicine, Department of Medicine and Sciences of Aging, "G. d'Annunzio" University, \\ Chieti 66100, Italy \\ ${ }^{3}$ Ce.S.I. Biotech, Aging Research Center, "G. d'Annunzio" University Foundation, Chieti 66100, Italy \\ ${ }^{4}$ Department of Experimental and Clinical Sciences, "G. d'Annunzio" University, Chieti 66100, Italy \\ ${ }^{5}$ General and Thoracic Surgery, "SS Annunziata" Hospital, Chieti 66100, Italy \\ "These authors have contributed equally to this work \\ Correspondence to: \\ Emma Di Carlo, e-mail: edicarlo@unich.it \\ Keywords: cytokines, lung cancer, tumor microenvironment, inflammation, immunotherapy \\ Received: October 15, $2014 \quad$ Accepted: November 20, $2014 \quad$ Published: January 03, 2015
}

\section{ABSTRACT}

Current therapies for Non-Small Cell Lung Cancer (NSCLC) still fail to significantly increase its survival rate. Here we asked whether Interleukin(IL)-27, which has revealed powerful antitumor activity and is toxicity-free in humans, is a promising therapeutic choice for NSCLC patients.

IL-27's effects were tested on Adenocarcinoma (AC) and Squamous Cell Carcinoma (SCC) cell lines and xenograft models. IL-27Receptor(R) expression was assessed in lung tissues from 78 NSCLC patients.

In vitro, IL-27 was ineffective on cancer cell proliferation or apoptosis, but fostered CXCL3/GROY/MIP2 $\beta$ expression. In vitro and in vivo, IL-27 down-regulated stemness-related genes, namely SONIC HEDGEHOG in AC cells, and OCT4A, SOX2, NOTCH1, KLF4 along with Nestin, SNAI1/SNAIL, SNAI2/SLUG and ZEB1, in SCC cells. In vivo, IL-27 hampered both AC and SCC tumor growth in association with a prominent granulocyte- and macrophage-driven colliquative necrosis, CXCL3 production, and a reduced pluripotency- and EMT-related gene expression. Myeloablation of tumorbearing hosts mostly abolished IL-27's antitumor effects. In clinical samples, IL-27R expression was found in AC, SCC, pre-cancerous lesions and tumor infiltrating myeloid cells, and correlated with advanced stages of disease.

Our data suggest that even immunocompromised or advancer NSCLC patients may benefit from IL-27's antitumor properties based on its ability to drive myeloid cells towards antitumor activities, and down-regulate stemness- and EMT-related genes in cancer cells.

\section{INTRODUCTION}

Lung cancer is the leading cause of cancer induced mortality worldwide $[1,2]$. Non-small cell lung cancers (NSCLC), particularly, adenocarcinoma (AC) and squamous cell carcinoma (SCC), are the most frequently diagnosed histotypes [1, 3]. New targeted therapies have been developed and some are currently used to treat advanced
$\mathrm{AC}$, but are unsuitable for SCC $[4,5]$. Moreover, not all AC patients benefit from these treatments [5]. Development of effective and well tolerable immunotherapies to replace or be combined with surgery, radiotherapy or personalized treatments may be of great value. In the last few years, Interleukin(IL)-27, a member of the IL-12 family of cytokines, with important roles in both innate and adaptive immunity $[6,7]$, has revealed potent antitumor effects in the 
form of anti-proliferation, anti-angiogenesis, and immune system stimulation in a variety of tumors [8-10]. Its overexpression in murine Lewis lung carcinoma line 1 (LLC1) cells induces a specific cytotoxic $\mathrm{T}$ cell and antibody response in vivo, and also activates non-immunological mechanisms reducing cancer cell motility and migration [11]. Inhibition of AC cell migration, together with downregulation of pro-angiogenesis genes by IL-27 has also been reported in the human A549 AC cell line [12]. Moreover, murine IL-27 gene-transfected LLC1 cells have been used to generate an autologous cell vaccine boosting an efficient $\mathrm{T}$ lymphocyte activation and IFN $\gamma$ production [13]. However, definitive in vivo proof of IL-27's efficacy in pre-clinical models of human lung AC and SCC is still lacking.

We here investigate the in vitro and in vivo effects of IL-27 on the regulation of angiogenesis-, stemness- and epitelial-mesenchymal transition (EMT)-related genes in human $\mathrm{AC}$ and SCC cell lines and lung tumors grown in $\mathrm{B} / \mathrm{T}$ cell deficient mice. Furthermore, by means of molecular biology and immunohistochemical studies, we have assessed IL-27Receptor(R) expression in lung cancer samples and analyzed the rationale for a future IL-27 application in the clinical setting of NSCLC.

\section{RESULTS}

\section{Human lung AC and SCC cell lines express IL- 27R and respond to IL-27 up-regulating CXCL3 expression and down-modulating stemness- and EMT-related genes}

Since AC and SCC are the most common histotypes of lung cancers, $\sim 85 \%$ of NSCLC $[1,3]$, we looked to see whether IL-27 acts as an antitumor agent in these forms.

Expression of both chains of the IL-27R, gp130 and WSX-1 (TCCR, IL-27R $\alpha$ ), was investigated, by flow cytometry, in a series of cell lines derived from human lung AC, namely A549, GLC82, Calu-6 or from SCC, namely Calu-1 and SK-MES. As shown in Figure 1A and $1 \mathrm{~B}$, Calu- 6 and SK-MES lines expressed the highest levels of both chains (gp130: 68\% and 65\%; WSX-1: $97 \%$ and $70 \%$ respectively) and were therefore chosen as representative of $\mathrm{AC}$ and $\mathrm{SCC}$ histotypes for the subsequent experiments.

We began by determining whether IL-27 affects the in vitro proliferation or apoptosis of these lines by culturing them with or without human (h) recombinant (r) hrIL-27 for 120 hours, and harvesting an aliquot every 24 hours to be analyzed for CFSE intracellular staining and for apoptosis. In both lines hrIL-27 was unable to directly modulate proliferation or apoptosis (not shown).

We next investigated whether IL-27 regulated, in both lines, sets of genes shaping tumor malignancy and specifically related to angiogenesis, stemness and invasiveness.

IL-27's ability to modulate angiogenesis-related genes in different cancer cell types, leading to anti-angiogenic effects in vivo, has been documented by us and others [8-10]. Unexpectedly, in both Calu-6 and SK-MES lines, hrIL-27 treatment considerably $(P<0.05)$ up-regulated, 18.53 and, 13.7 times respectively, the mRNA expression of CXCL3 (Figure 1C), also known as Growth-Related Oncogene (GRO)3, GRO protein gamma $(G R O \gamma)$ and Macrophage Inflammatory Protein 2 beta (MIP2 $\beta$ ), an angiogenic ELR ${ }^{+}$ CXC chemokine [14], identified as a powerful neutrophil chemoattractant $[15,16]$, and also driving migration and adhesion of monocytes and macrophages [17].

Other angiogenesis-related genes were differently regulated by IL-27 in the two lines (Figure 1C). In SK-MES cells only, hrIL-27 up-regulated $I F N \gamma(6.13$ times) and down-regulated LAMA5, encoding for Laminin- $\alpha 5$ (4.5 times), and THBS1, encoding for Thrombospondin-1 (8.64 times), whereas in Calu6 cells, hrIL-27 selectively up regulated Cadherin 5 (CDH5), i.e.: Vascular Endothelial (VE)-Cadherin (4.5 times), and the Tissue Inhibitor of Metalloproteinase-1 (TYMP-1) (5.3 times) encoding for Platelet Derived Endothelial Cell Growth Factor 1 (ECGF1).

Within a range of stemness-related genes (including NANOG, BMI1, CD44v6, c-MYC, see Supplementary information), in SK-MES cells, hrIL-27 significantly $(P<0.05)$ down-regulated mRNA expression levels of Octamer-binding Transcription Factor 4A, OCT4A (5.7 times), SRY (sex determining region Y)-box 2, SOX2 (4.0 times), SOX9 (7.1 times), Notch homolog 1, NOTCH1 (7.0 times), and Krüppel-like factor 4, KLF4 (6.1 times) (Figure 1D), whereas in Calu-6 cells it only down-modulated mRNA expression of Sonic Hedgehog, SHH (4.2 times) (Figure 1E). Moreover, in SK-MES cells, hrIL-27 down-modulated mRNA expression levels of Nestin (6.7 times), associated with cell stemness and EMT $[18,19]$, and within the ZEB, SNAIL and TWIST families of EMT-activating transcription factors [20, 21], hrIL-27 down-modulated mRNA expression of Snail family zinc finger 1, SNAII/SNAIL (5.0 times), Snail family zinc finger 2, SNAI2/SLUG (4.3 times), and Zinc finger E-box binding homeobox 1, ZEB1 (5.0 times) (Figure 1F), whereas the expression of $c-M E T$, also involved in EMT $[22,23]$, and that of ZEB2, TWIST1, and TWIST2 remained unaffected.

\section{IL-27 hinders tumour growth in pre-clinical xenograft models of lung cancer in association with a remarkable colliquative necrosis and apoptotic events}

In vivo studies using pre-clinical models of severe combined immunodeficient SCID/NOD and T-cell deficient athymic-nude mice, s.c. injected with Calu-6 and SK-MES cell lines respectively, showed that hrIL-27 considerably reduced tumor growth in both models. In particular, the mean tumor volume $(\mathrm{mtv}) \pm$ standard error (SE) of Calu-6 tumors grown 
A
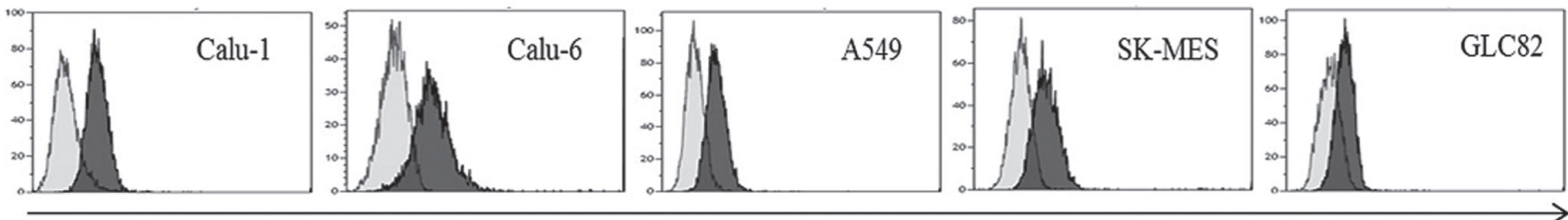

B

gp130

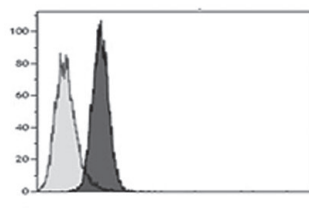

C

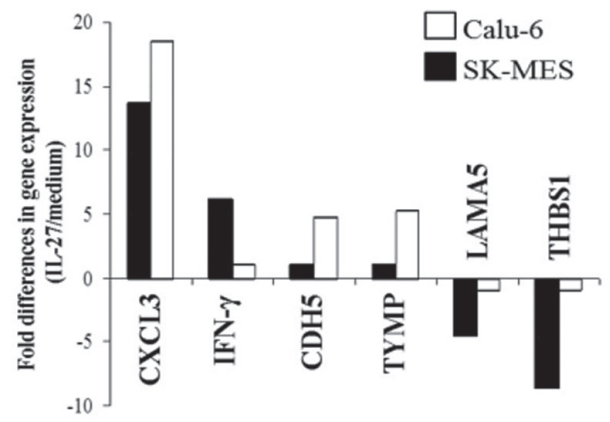

E

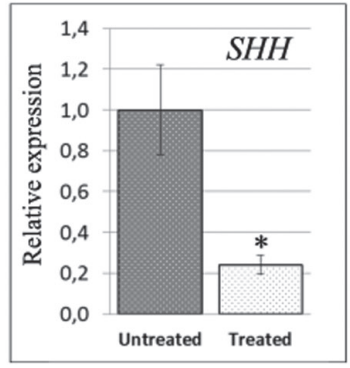

$\mathrm{F}$

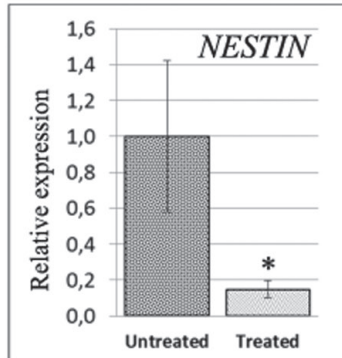

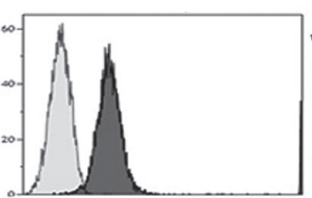

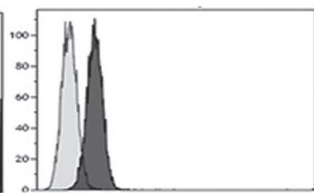

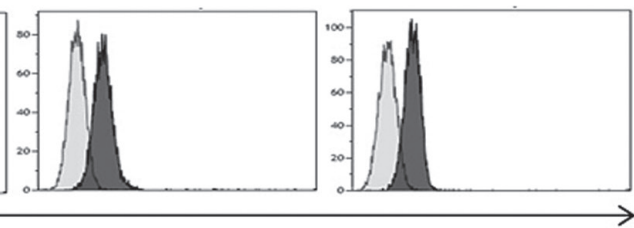

WSX-1

D
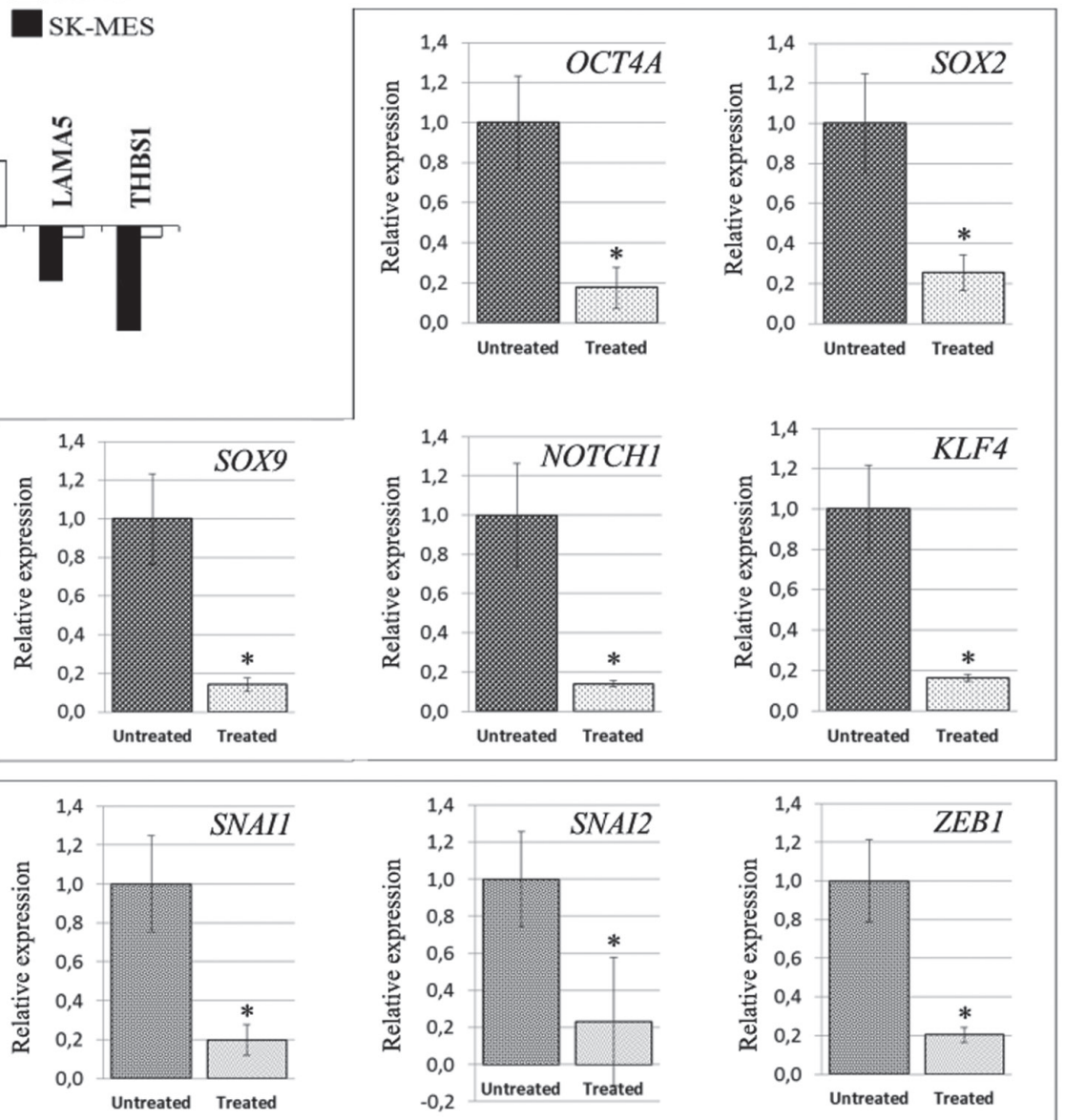

Figure 1: Expression of IL-27R in Human Lung Carcinoma Cell Lines, and IL-27's Effects on Angiogenesis, Stemnessand EMT-Related Gene Expression in Calu-6 and SK-MES Cell Lines. Expression of gp130 (A) and WSX-1 (B) was analyzed in human lung carcinoma cell lines by flow cytometry. Open profile: gp130 (top) and WSX-1 (bottom) staining. Dark profile: isotype matched mAb staining. The mean percentage of gp 130 expression was $65 \%$ in SK-MES and $64 \%$ in Calu- 1 cells, $68 \%$ in Calu- $6,44 \%$ in GLC82 and 26\% in A549 cells. The mean percentage of WSX-1 was 70\% in SK-MES, 66\% in Calu-1, 97\% in Calu-6, 77.5\% in GLC82 and $78 \%$ in A549 cells. Experiments were performed in triplicate. (C) Regulation of angiogenesis-related gene expression in SK-MES (black bars) and Calu-6 (white bars) cells upon hrIL-27 treatment, as assessed by PCR Array. Histogram represents fold differences in gene expression of individual mRNA between cells cultured in the presence or absence of hrIL-27. Pooled results \pm SD from two experiments performed in duplicate are shown. Regulation of stemness-related gene expression in SK-MES cells (D) and in Calu-6 cells (E) upon hrIL27 treatment, as assessed by real-time RT-PCR. (F) Regulation of EMT-related gene expression in SK-MES cells upon hrIL-27 treatment. Results are representative of three independent experiments. $* P<0.05$. 
in hrIL-27-treated mice was $54.22 \pm 24.2 \mathrm{~mm}^{3}$ versus $241 \pm 69 \mathrm{~mm}^{3}$ of tumors from controls $(P=0.0336)$ (Figure 2A), whereas the $\mathrm{mtv} \pm \mathrm{SE}$ of SKMES tumors was $59.08 \pm 13.1 \mathrm{~mm}^{3}$ versus $123.3 \pm 24.5$ $\mathrm{mm}^{3}$ of tumors from controls $(P=0.0469)$ (Figure $\left.2 \mathrm{~B}\right)$.

To get an insight into the mechanisms underlying the in vivo antitumor effects of IL-27, tumor growth/ suppression areas were histopathologically analyzed. The histologic features of Calu-6 and SK-MES tumors from control mice, recalled human poorly-differentiated AC and SSC, respectively. Tumors harvested from hrIL-27treated mice displayed wide areas of colliquative necrosis characterized by a prominent reactive cell infiltrate, (Figure 2C and 2D), in addition, SK-MES tumors also presented evident alterations in cancer cell morphology ranging from a spindle to a polygonal-round phenotype (Figure 2D). Inflammatory infiltrates were wider in both Calu-6 and SK-MES tumors from hrIL-27-treated mice than in control tumors, because of the significant $(P<0.05)$ increase in their granulocyte and macrophage content, along with cancer cell expression of CXCL3 (Figure 2C and 2D) (Table 3). In addition to the areas of colliquative necrosis, frequent apoptotic features were evidenced, by the TUNEL assay, close to granulocytes identified by their segmented nuclei, (Figure 2C and 2D), in both Calu-6 and SK-MES tumors from hrIL-27-treated mice (Figure 2C and 2D) (Table 3).

To understand the molecular mechanism underlying apoptotic events in vivo, we next assessed in tumors from hrIL-27-treated and control mice the expression of apoptosis-inducing proteins Tumor Necrosis Factor (TNF) $\alpha$ and TNF-Related Apoptosis Inducing Ligand (TRAIL). Immunostainings revealed that TRAIL was almost undetectable, while TNF $\alpha$ expression was distinct to strong, in the foci of reactive infiltrates, in both tumor types harvested from hrIL-27-treated mice (Figure 2C and 2D) (Table 3).

Lastly immunohistochemical analyses revealed that the microvascular network of Calu-6 tumors from hrIL-27-treated mice was similar to that of the controls whereas that of SK-MES tumors from hrIL-27-treated mice was clearly impaired (Figure 2C and 2D) (Table 3) in association with a weakened laminin network and a faint, but distinct cancer cell expression of IFN $\gamma$ (Figure 3A).

\section{IL-27 down-modulates stemness- and EMT- related genes, particularly in SCC tumors}

To assess whether IL-27 regulation of pluripotencyand EMT-related genes also occurs in vivo at protein level, we carried out immunohistochemical analyses of tumors from hrIL-27- and PBS-treated mice.

In Calu-6 tumors from hrIL-27-treated animals, the percentage of cancer cells displaying a distinct to strong $\mathrm{SHH}$ staining was decreased compared with control tumors (Figure 3B), whereas in SK-MES tumors from treated animals, the percentage of cells endowed with a distinct to strong nuclear staining for OCT4A, NOTCH1, and KLF4 was clearly decreased (Table 3 ) as was reduced the percentage of tumor cells displaying both nuclear and cytoplasmic SOX2 positivity and nuclear SOX9 positivity (Figure 3C) (Table 3). Expression of Nestin was weakened in cancer cells forming SK-MES tumors from IL-27treated mice (Figure 3D). Nuclear and cytoplasmic SNAI1 stainings were dramatically and moderately reduced respectively, and the percentage of cancer cells endowed with a distinct to strong nuclear SNAI1, SNAI2, and ZEB1 staining also significantly $(P<0.05)$ decreased following hrIL-27 treatment (Figure 3D), whereas E-Cadherin expression was reinforced in tumors from hrIL27-treated mice (Figure 3D) (Table 3).

\section{Myeloablation by treosulfan thwarts the in vivo anti-lung cancer effects of IL-27}

To assess whether granulocytes and macrophages may, as suggested by the morphological data, account for the anti-lung cancer effects of IL-27 in vivo, we next repeated tumor growth experiments in mice pre-treated with myeloablative doses of treosulfan to obtain a severe or complete depletion of bone marrow cells [18].

These experiments revealed that after this treatment both Calu-6 and SK-MES tumors grew similarly in hrIL27-treated and control mice. In particular, the mtv \pm SE of Calu-6 tumors harvested from myeloablated and IL-27treated mice was $153.4 \pm 29.9 \mathrm{~mm}^{3}$ versus $169 \pm 33.99$ $\mathrm{mm}^{3}$ of tumors from myeloablated controls (Figure 4A). The $\mathrm{mtv} \pm \mathrm{SE}$ of SK-MES tumors from myeloablated and IL-27-treated mice was $34.6 \pm 4 \mathrm{~mm}^{3}$ versus $33.6 \pm 5.65$ $\mathrm{mm}^{3}$ of tumors from myeloablated controls (Figure 4B). Of note, both Calu-6 and, particularly, SK-MES tumors grown in myeloablated control mice were smaller than tumors developed in not-myeloablated control mice (Calu-6: $P=0.0317$ and SK-MES: $P=0.0159$ ).

Histological features of both Calu-6 and SKMES tumors developed in myeloablated hrIL-27-treated mice were similar to those from myeloablated controls. However, both histotypes, developed in myeloablated mice, independently from hrIL-27-treatment, presented small ischaemic necrotic foci (Figure 4C) in association with an evident (vessel counts: $3 \pm 2$ in Calu-6, and $5 \pm 2$ in SK-MES tumors from myeloablated controls, versus 9 \pm 3 in Calu-6, and $12 \pm 4$ in SK-MES tumors from nonmyeloablated controls; $P<0.05$ ) decrease of the whole vascular supply (Figure 4C). These tumours were almost devoid of granulocyte and macrophage content (Figure 4C). CXCL3 was still firmly expressed by tumor cells in both Calu-6 and SK-MES tumors from myeloablated and hrIL-27-treated mice (Figure 4C), while a faint IFN $\gamma$ production was only detected in the latter. 

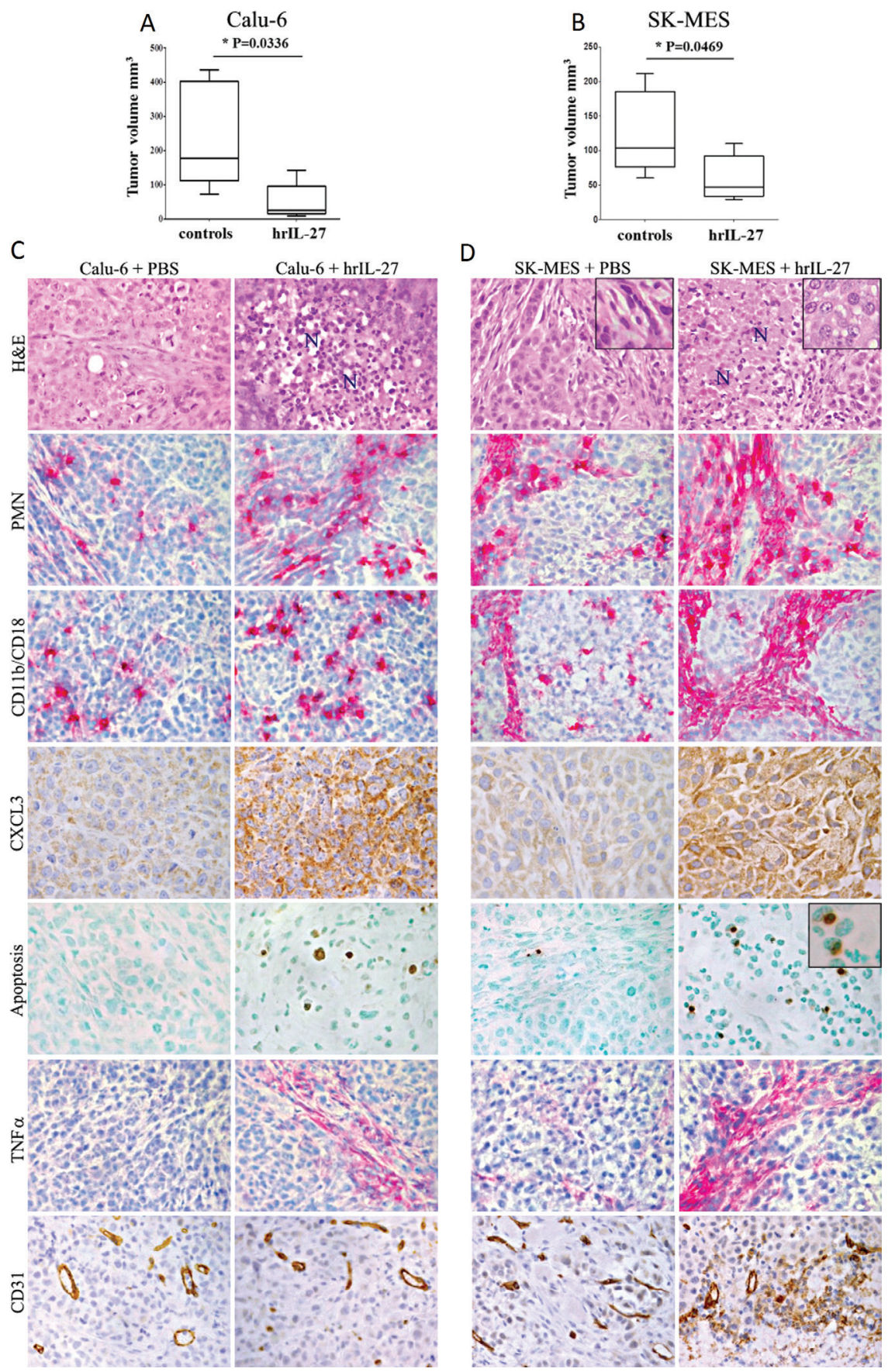

Figure 2: Antitumor Effects of IL-27 in Immunodeficient Pre-Clinical Models of Lung AC and SCC and Histopathological Analyses of the Tumor Growth or Regression Areas. Volume of tumor masses developed in SCID/NOD (A) and athymic nude mice (B) injected with the Calu-6 and SK-MES cell lines respectively, and subsequently treated with PBS or hrIL-27. Results are representative of three independent experiments. ${ }^{*} P<0.05$. Histological and immunohistochemical analyses $(\mathbf{C}, \mathbf{D})$ revealed that Calu-6 and SK-MES tumors grown in PBS treated mice had the features of poorly-differentiated human lung AC (rare glandular lumen) and SSC (epithelial cells with spindle morphology, inset), and displayed frequent mitotic figures, whereas both tumors from hrIL-27-treated mice showed wide areas of colliquative necrosis $(\mathrm{N})$ and, particularly for SK-MES tumor cells, the acquisition of a more polygonal-round morphology (inset). Both histotypes from hrIL-27-treated mice showed a prominent granulocyte (PMN) and macrophage (CD11b/CD18) infiltrate, along with a strong CXCL3 production by tumor cells in comparison with control tumors. Following hrIL-27 treatment apoptotic events, close to cells endowed with segmented nuclei (inset), were frequent, as assessed by the TUNEL assay, in both histotypes, whereas they were almost absent in control tumors, and a distinct to strong expression of $\mathrm{TNF} \alpha$ was detected at the sites of reactive infiltrates, whereas it was lacking in control tumors. The microvascular network supplying Calu-6 tumors from hrIL-27-treated mice was similar to that of control tumors. By contrast, in SK-MES tumors from hrIL-27-treated mice it was evidently impoverished, in comparison with control tumors. (C and D: H\&E, PMN, CD11b/CD18, TNF $\alpha$, and CD31 at X400; C and D: CXCL3, Apoptosis, and H\&E insets at X630; D: Apoptosis inset: X1000). 
A

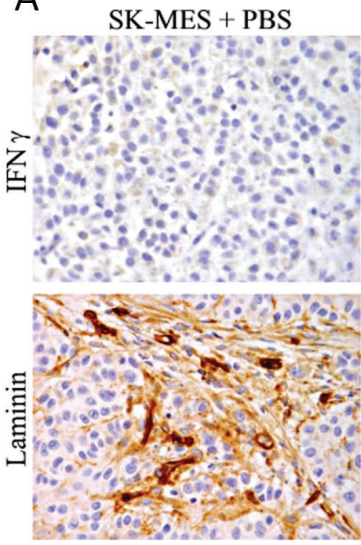

C
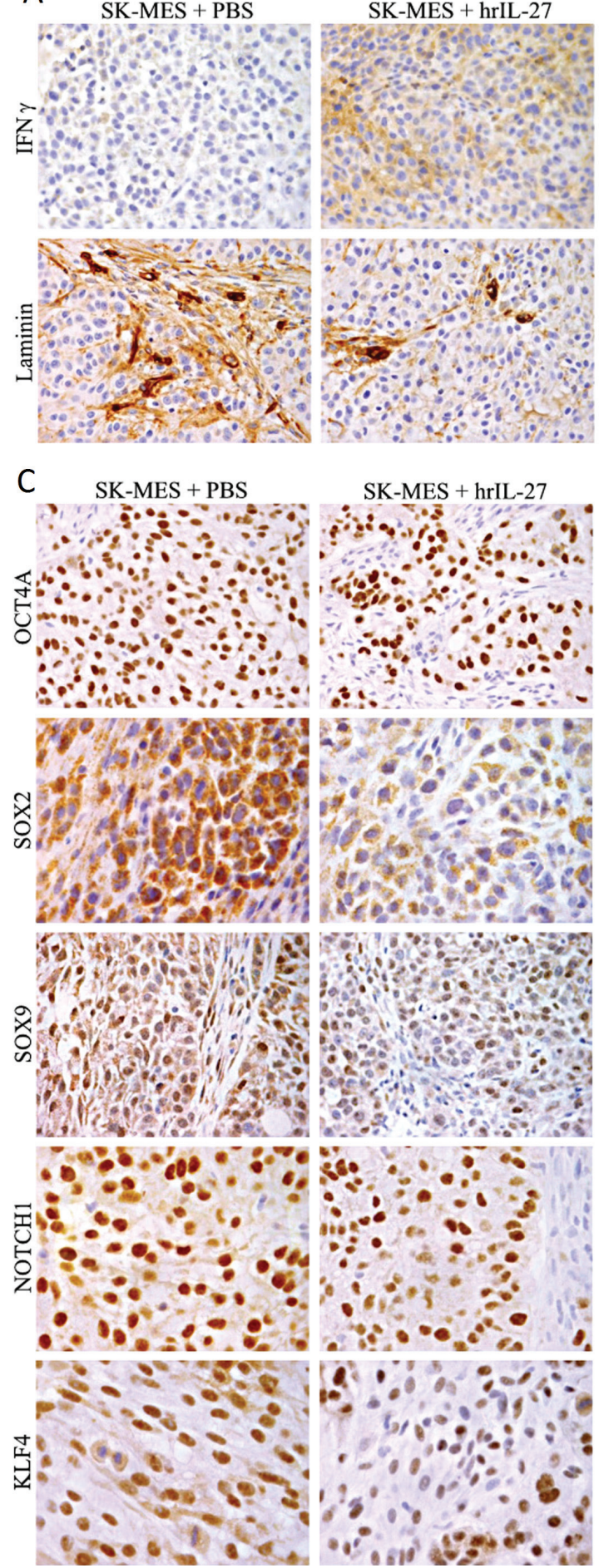

SK-MES + hrIL-27
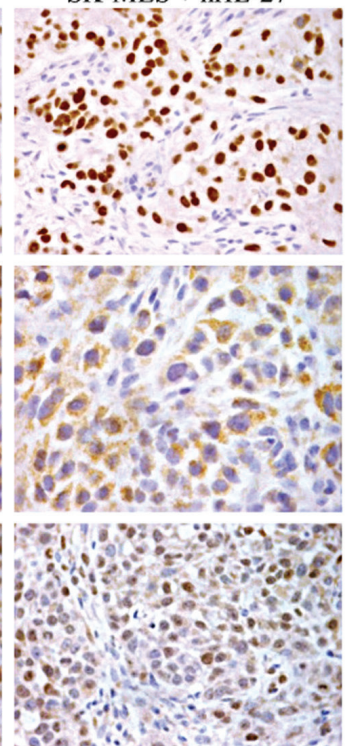

B

D

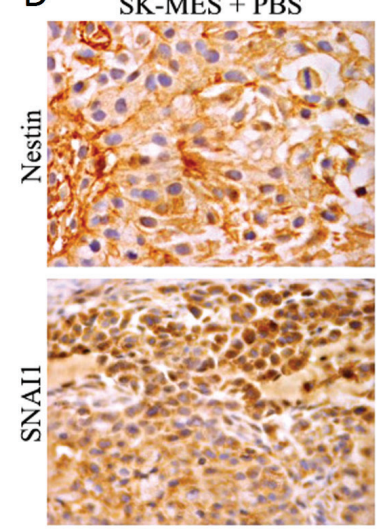

SK-MES + hrIL-27
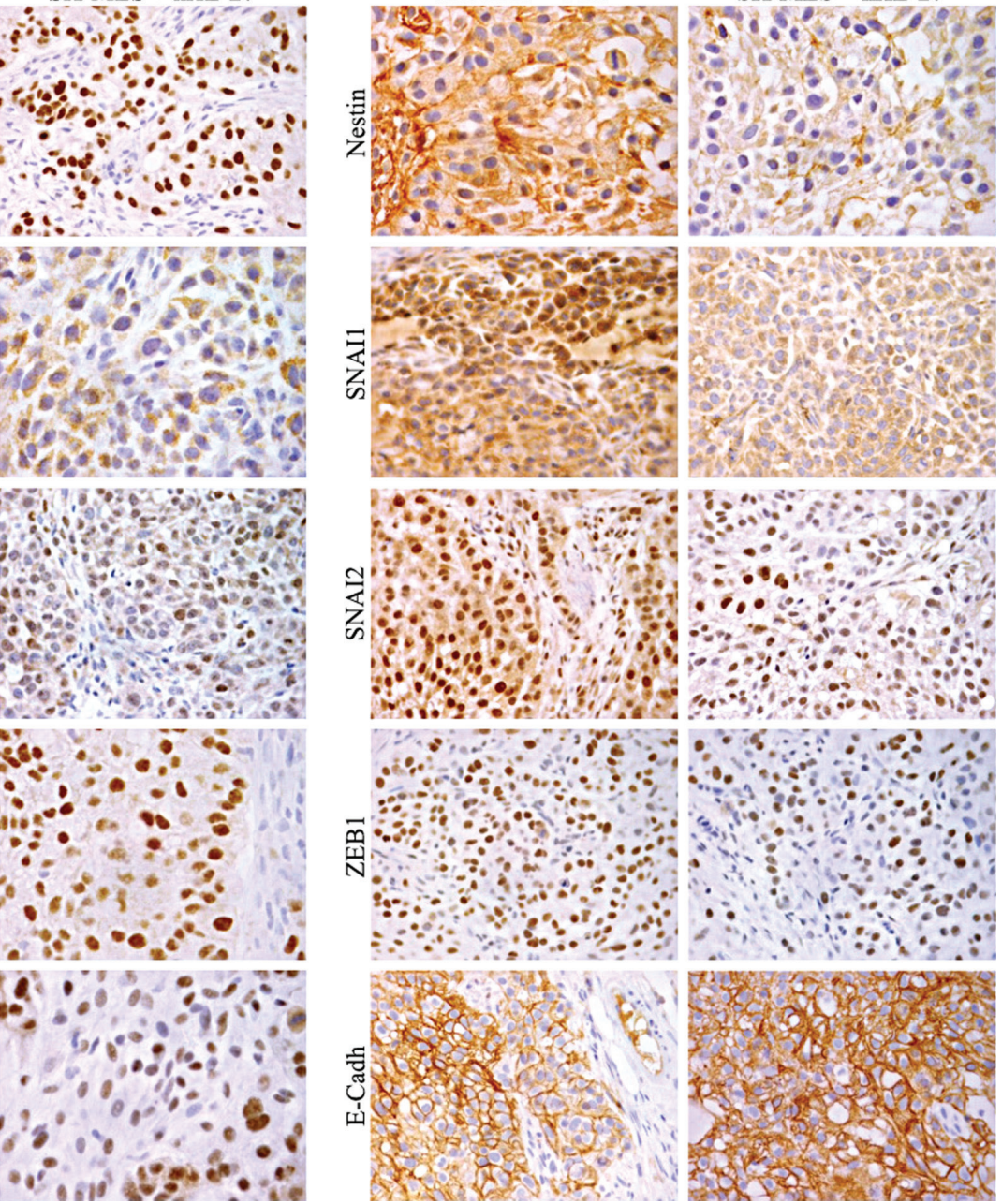

Figure 3: Expression of IFN $\gamma$ and Down-Modulation of Stemness Genes and EMT-Regulating Transcription Factors by IL-27 in SK-MES Tumors in vivo. (A) An evident weakness of the laminin network and a slight, but distinct expression of IFN $\gamma$ were observed in SK-MES tumors harvested from hrIL-27 treated mice in comparison with control tumors. (X400). (B) In comparison with Calu-6 tumors from control mice, those from hrIL-27-treated mice presented a reduced percentage of cancer cells endowed with a distinct to strong expression of SHH. (X630). (C) In comparison with SK-MES tumors from control mice, those from hrIL-27-treated mice showed a reduced percentage of cancer cells endowed with a distinct to strong expression of OCT4A, SOX2, SOX9, NOTCH1, and KLF4. (OCT4A and SOX9: X400; SOX2, NOTCH1, and KLF4: X630). (D) Expression of Nestin was faint following hrIL-27 treatment, while it was distinct to strong in control tumors. Nuclear expression of SNAI1, SNAI2, and ZEB1 was less frequent in tumors from hrIL-27 treated mice than in control tumors, and the tumor cell surface expression of E-Cadherin was stronger in the former than in the latter. (Nestin: X630; SNAI1, SNAI2, ZEB1, and E-Cadherin: X400). 

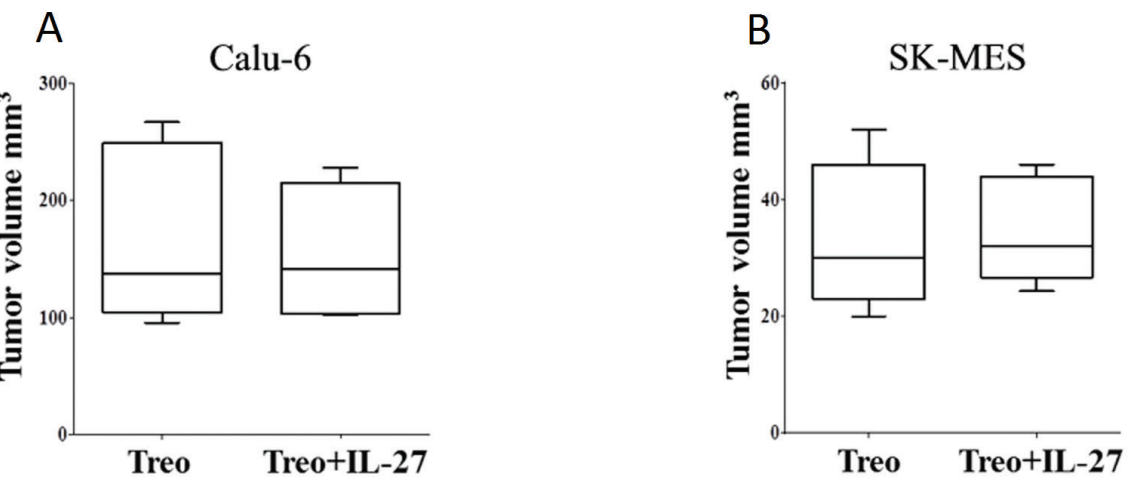

C
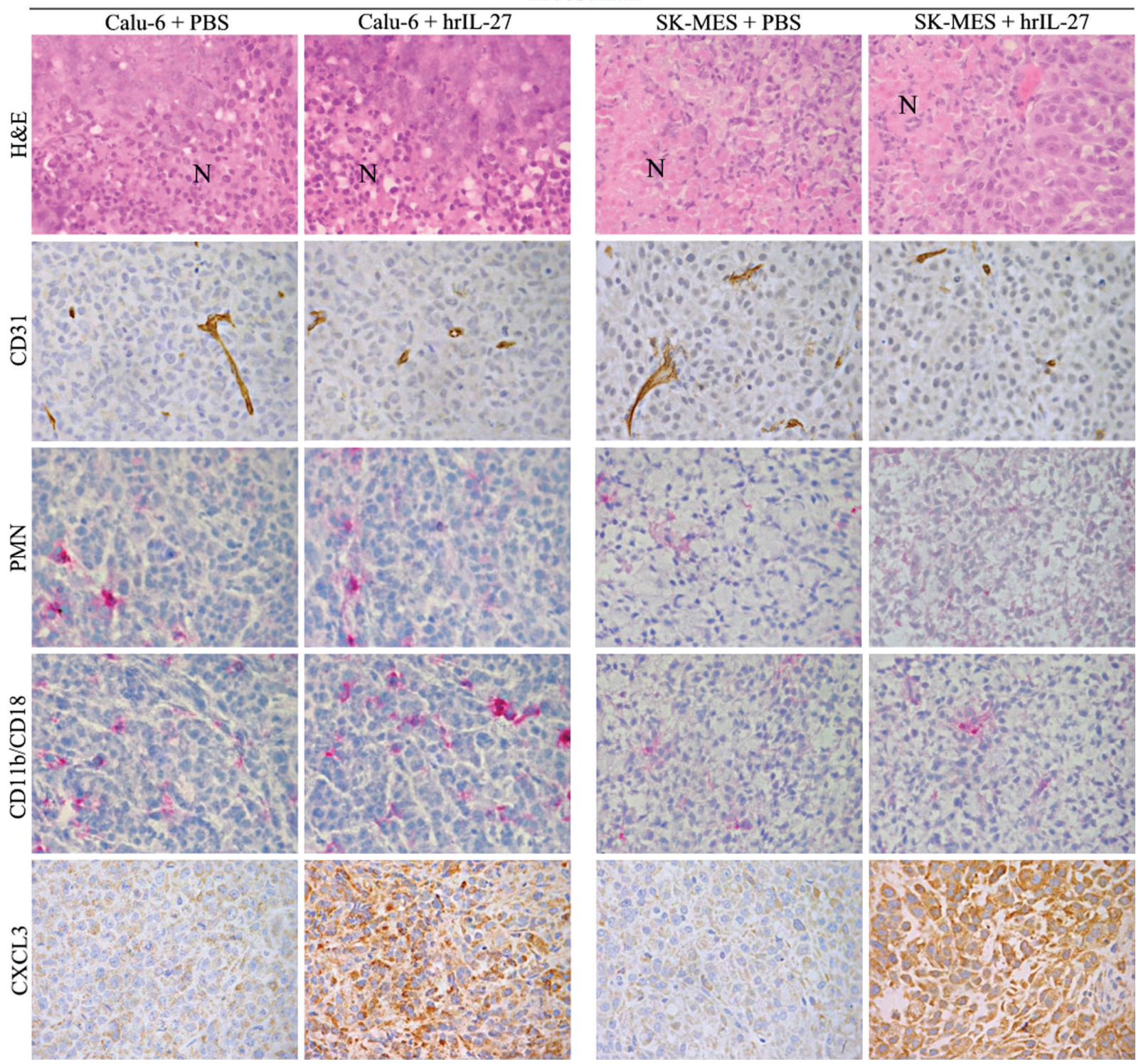

Figure 4: Loss of IL-27 Anti-Lung Cancer Effects in Myeloablated Mice and Histopathological Features of their Tumors. The mean volume of Calu-6 (A) and SK-MES (B) tumors grown in myeloablated mice treated with hrIL-27 was not significantly different (Calu-6: $P=0.0317$ and SK-MES: $P=0.0159$ ) from that of tumors grown in myeloablated PBS-treated mice. Results are representative of three independent experiments. (C) Histopathological analyses revealed that both Calu-6 and SK-MES tumors from hrIL27-treated and myeloablated mice developed small foci of ischaemic necrosis $(\mathrm{N})$ as their respective control tumors, in association with a rarefied vascularization. Tumor infiltrating granulocytes and macrophages were barely detected in both histotypes from IL-27-treated and PBS-treated, myeloablated mice, in spite of the distinct CXCL3 production found in both histotypes from hrIL-27-treated mice in comparison with control tumors. (X400). 


\section{Human lung $\mathrm{AC}$ and $\mathrm{SCC}$, and their precursor lesions express IL-27R in neoplastic and dysplastic cells, microvessels and tumor-associated reactive cells}

To determine whether lung cancer patients could benefit from IL-27's antitumor effects, we next immunohistochemically evaluated the expression and distribution of IL-27R in AC and SCC tissue sections. Since expression of gp130 has been documented in lung cancer [24, 25], we only assessed IL-27R $\alpha$ expression in both cancerous and normal lung samples (from both cancer and control patients). In the normal tissue, it was basically found in mononuclear/macrophage-like cells fluctuating within alveolar walls (Figure 5D). Normal bronchial epithelia firmly expressed $I L-27 R \alpha$ mRNA, whereas in neoplastic samples it was expressed by the majority of AC, 90\%, and SCC, 84\% (Table 2) (Figure 5A and 5D). Furthermore, within AC, metastatic tumors revealed significantly $(P<0.05)$ higher expression levels of $I L-27 R \alpha$ mRNA than normal bronchial epithelia (Figure 5B). Notably, IL-27R $\alpha$ expression in microdissected bronchial epithelium from normal samples of patients with lung cancer was analogous to that in control patients. These molecular data showed a good correlation $(\rho=0.82)$ with the immunohistochemical findings.

IL-27R $\alpha$ expression by the primary tumor was significantly associated with lymph node status $(P=0,001)$, and advanced stages of disease $(P=0,02)$ as assessed by Fisher's exact test, whereas no significant association was observed with patient age or smoking history.

Immunohistochemistry also revealed IL-27R $\alpha$ expression in AC and SCC precursor lesions, namely atypical adenomatous hyperplasia (AAH) and severe dysplasia, squamous metaplasia (SM), squamous cell carcinoma in situ (SCIS) (Figure 5D), respectively (Table 1). IL-27R $\alpha$ expression may also be found in microvessels and infiltrating immune cells (Figure 5C), mostly identifiable as $\mathrm{CD}^{+} 8^{+}$monocytes/macrophages (Figure 5D) and CD11 $\mathrm{c}^{+}$myeloid dendritic cells. They were found in the stroma of both AC and SCC, scattered or within the lymph node-like structures, known as tertiary lymphoid structures (TLS) (Figure 5D) [26, 27]. $\mathrm{CD} 15^{+}$granulocytes that may be found in necrotic foci of rapidly growing tumors also expressed IL-27R $\alpha$ (Figure 5D).

\section{DISCUSSION}

AC and SCC constitute the commonly diagnosed lung cancer histotypes $[1,2]$, but their management still results in low overall cure rates, suggesting the need for novel therapeutic approaches. The idea of strengthening patient's immune system to fight cancer is of growing interest for oncologists [28]. Our data indicate that IL-27, a well-tolerated and toxicity-free cytokine [9] may provide a new therapeutic option in NSCLC. Previous studies assessing IL-27's effects in lung cancer have used mouse autograft models $[11,13]$ or, in vitro experiments with both murine and human lung AC cell lines [11, 12]. Our data confirm, in pre-clinical xenograft models of human lung AC and SCC, the anti-lung cancer effects of IL-27. They have also revealed unforeseen implications for its immunological antitumor capability in the form of I. boosting the potent granulocyte/macrophage chemoattractant CXCL3, in both AC and SCC cells, leading to intratumoral myeloid cell recruitment and activation, and II. re-education of these immune cells from the status of "cancer feeder", and host-detrimental $[29,30]$ towards that of "cancer killer", thus host-beneficial [30-32].

Tumor destruction by the prominent neutrophil and macrophage influx mediated by CXCL3 [15-17] overcomes, at least in our setting, its well-known proangiogenic effects [14], since microvessel density remained unaltered in AC and slightly decreased in SCC tumors from IL-27-treated animals, when compared with controls. Anti-angiogenesis has a marginal or nil role in IL-27's anti-lung cancer efficacy, and apart from a slight $I F N \gamma$ induction and $L A M I N I N-\alpha 5$ down-regulation observed in SCC cells, IL-27 even down-regulates the angiogenesis inhibitor THROMBOSPONDIN-1 [33] in SK-MES cells, and up-regulates VE-CADHERIN [34] and the pro-angiogenesis gene TYMP-1, encoding for ECGF1 [35], in Calu-6 cells, but without significant in vivo consequences for tumor vascularity.

Granulocytes and macrophages are endowed with IL-27R, and may respond to IL-27 by increasing their oxidative burst and cytokine production [36-38], suggesting that the range of action for this cytokine is not restricted to $\mathrm{T}$ cells, the key mediators of its antitumor effect in an immune-intact host [9]. Our results provide the first evidence that intratumor recruited and activated myeloid cells may, in a B/T cell-deficient host, take the place of T lymphocytes in mediating IL-27's antitumor activity, leading to a dramatic colliquative necrosis, and $\mathrm{TNF} \alpha$-associated apoptotic events in both AC and SCC.

While extending to human SCC in vivo the finding of IL-27's down-modulation of EMT transcription factors such as SNAI1, SNAI2 and ZEB1 [20, 21], our discoveries identify a novel role for IL-27 as a negative regulator of pluripotency genes such as $\mathrm{SHH}$ in human $\mathrm{AC}$ cells, and SOX2, OCT4A, NOTCH1, KLF4, SOX9 and Nestin $[18,19]$ in human SCC cells, both in vitro and in vivo. EMT, a key event during the early phases of invasion and metastatization, selects for stem cell property [39], which, in turn, may condition the self-renewal capability of a cancer and correlate with its aggressiveness [40, 41]. Down-regulation of critical pluripotency genes by IL-27 increases the propensity of cells to differentiate towards a less aggressive phenotype [42-44] as shown by their transition from a fibroblast-like to a polygonal-round E-Cadherin-positive phenotype. 
A

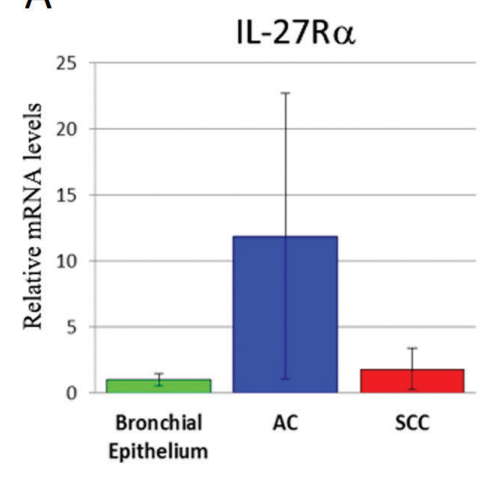

B

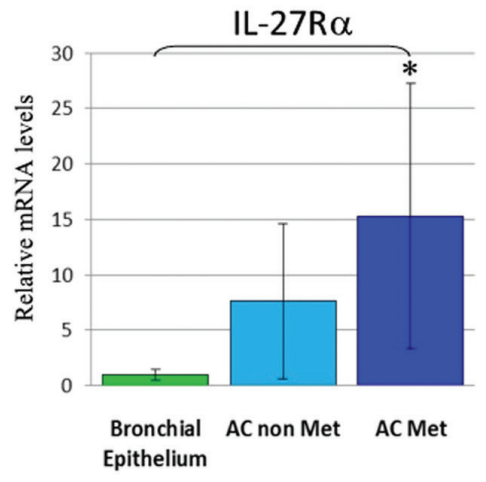

C

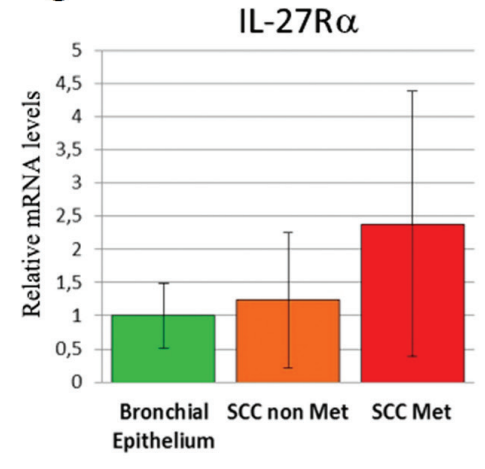

D

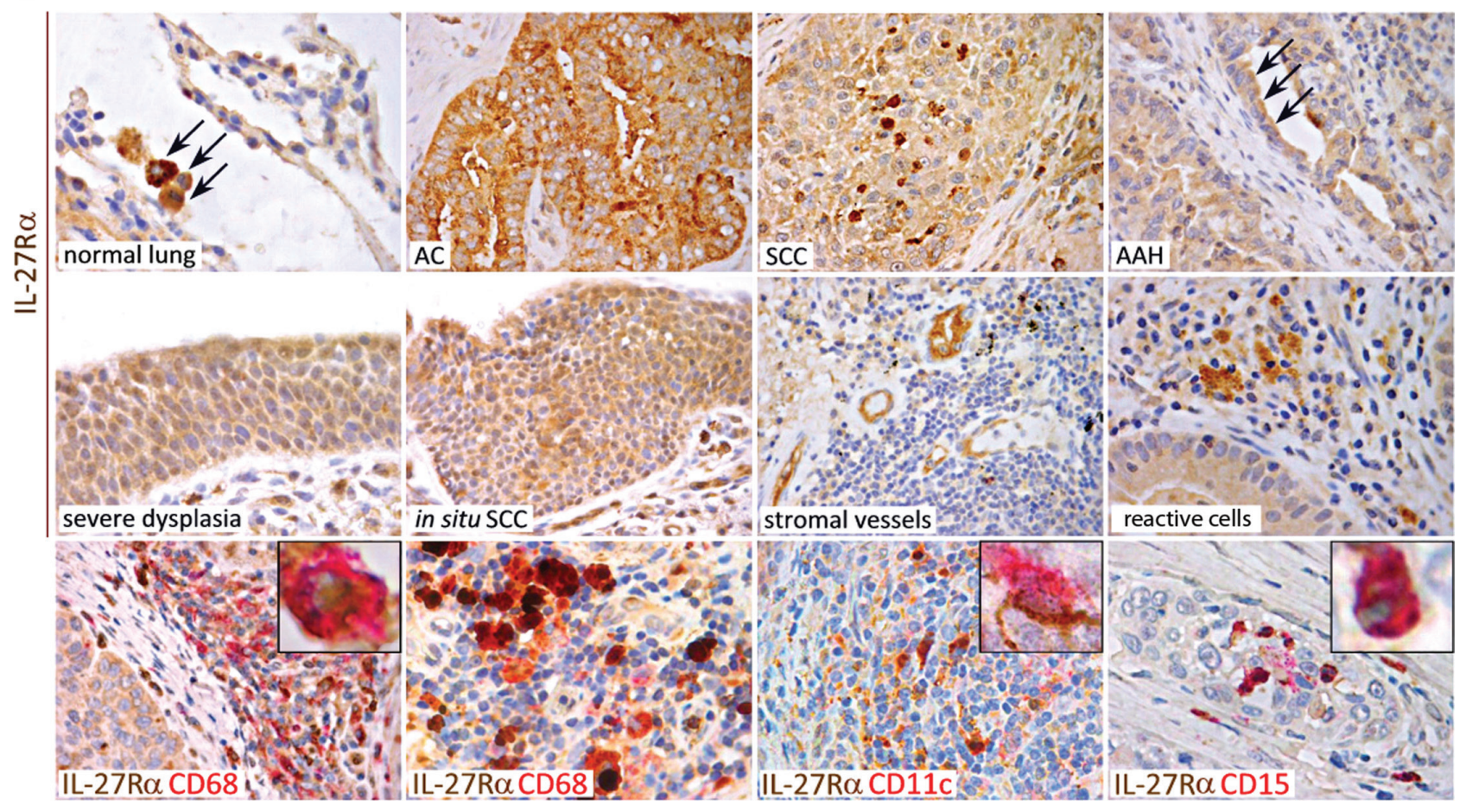

Figure 5: mRNA and Protein Expression of IL-27Ra in Human Normal Lung, Pre-Neoplastic Lesions, Lung AC and SCC. (A, B and C) Histograms representing the relative expression \pm SD of IL-27R $\alpha$ mRNA in microdissected neoplastic cell populations from groups of 10/12 samples of each cancer subtype: AC and SCC, in (A) or metastatic (Met) versus non-metastatic (non Met) primary AC (B), or Met versus non Met primary SCC (C) compared with histologically normal bronchial epithelium from the same patients, normalized with the housekeeping gene HPRT. One-way ANOVA for comparisons between normal bronchial epithelium, AC and SCC (A) $(P=1.0)$, or between normal bronchial epithelium, non-Met AC and Met AC (B) $(P=0.045, * P<0.05$ Tukey HSD Test compared with normal bronchial epithelium), or between normal bronchial epithelium, non-Met SCC and Met SCC (C) $(P=0.190)$. (D) Immunohistochemistry revealed that IL-27R $\alpha$ (brown) was expressed in monocyte/macrophage-like cells in the normal lung tissue (X630), in most of AC (X400) and SCC (X630) and frequently in dysplastic cells forming AAH (arrows) (X630), severe dysplasia (X630) and in situ SCC (X400). It may also be found in stromal small vessels (X400) and infiltrating reactive cells (X630), particularly in CD68 macrophages (red) (X630, inset at X1000) and CD11 $\mathrm{c}^{+}$myeloid dendritic cells (red) (X630, inset at X1000) scattered in the stroma (in the bottom left panel) or intermingled with lymphocytes in TLS (in the bottom middle panels). CD15 granulocytes (red) (in the bottom right panel), which may be found in the small necrotic foci of rapidly developing SCC, also express IL-27R $\alpha$ (brown dots) (X630, inset at X1000).

Tumor responsiveness to IL-27, however, is the prerequisite for its entry into clinical trials. Most $\mathrm{AC}$ and SCC express IL-27R, and those with N1 involvement are often endowed with higher expression levels. Dibra et al. observed that WSX-1 expression in tumors induces immune tolerance exerting pro-tumorigenic functions, independently from IL-27 [45]. Our data, drawn from patient samples, suggest that IL-27 may be used to overcome this drawback and be of particular benefit in advanced lung cancer stages. The myeloid cell mediated anti-lung cancer effects of IL27 may be exerted in humans, since in our samples IL-27R is not only expressed by cancer cells, and microvessels, but also by $\mathrm{CD} 15^{+}$granulocytes, $\mathrm{CD} 68^{+}$monocytes/ macrophages and $\mathrm{CD} 11 \mathrm{c}^{+}$myeloid dendritic cells scattered 
in the stroma or arranged in TLS. TLS have been associated with a favorable clinical outcome in NSCLC [26, 27] and IL-27 may promote, in these lymphoid structures, an efficient adaptive antitumor immunity.

Altogether, our results highlight novel aspects of IL-27's antitumor potential, specifically in NSCLC, such as the ability I. to drive myeloid cells towards antitumor activities, and II. down-regulate stemness genes, particularly in SCC cells, thus suppressing their selfrenewal potential. IL-27 may thus be proposed for clinical trials with the prospect of its clinical use in immunedefective or advanced NSCLC patients.

\section{MATERIALS AND METHODS}

\section{Ethics statement}

Animal experiments were performed at the IRCCS "San Martino" National Institute for Cancer Research, Genoa, in keeping with the National and International regulations (Italian Legislative Order 27/01/1992, n.116, European Economic Community Council Directive 86/609, OJL 358, Dec. 1, 1987). For studies on human tissues, written informed consent was obtained from patients. The study was approved by the Ethical Committee of the "G. d'Annunzio" University of Chieti (Italy), and Local Health Authority No.2, in the report n. 14 of 19/07/2012, and performed in accordance with the principles outlined in the Declaration of Helsinki.

\section{Patients and samples}

Premalignant and malignant lung samples were obtained from 78 untreated patients with operable NSCLC staged IA-IIIA according to the pTNM system [46]. NSCLC consisted of 33 AC (12/33 with N1 involvement) and 25 SCC (10/25 with N1 involvement). Our panel of 20 premalignant and 58 malignant lesions [47, 48], and patient's clinic-pathological characteristics [48, 49] are shown in Tables 1 and 2. Normal lung tissue was obtained from both lung cancer patients and control patients operated for other reasons. Sample collection and processing are described in the Supplementary information.

\section{Cell culture and flow cytometry}

Human lung SCC cell lines, Calu-1 and SK-MES, and AC cell lines, Calu-6, GLC82 and A549 (ATCC cell bank) were cultured in RPMI 1640 with 10\% FCS (Seromed Biochrom KG, Berlin, Germany). HrIL-27 (R\&D System, Abingdon, UK) was used at $100 \mathrm{ng} / \mathrm{ml}$ following titration experiments. Details on the assessment of IL-27R expression, tumor cell proliferation and apoptosis by flow cytometry are provided in the Supplementary information.

\section{Assessment of angiogenesis, stemness- and EMT- related gene expression by real-time $R T-P C R$}

RNA was extracted from Calu- 6 and SK-MES cells cultured for 24 hours in the presence or absence of hrIL27, using TRIZOL reagent (Invitrogen, Paisley, UK). Contaminant genomic DNA was removed by DNase treatment (Qiagen GmbH, Hilden, D). RNA was reversetranscribed with the RT ${ }^{2}$ First Strand cDNA Synthesis kit (SABioscience, Frederick, MD, USA). Experiments are described in the Supplementary information.

\section{Laser capture microdissection (LCM) and real-time RT-PCR}

We used the P.A.L.M. Micro Beam System (Bernried, Germany) for LCM of frozen sections from normal human lung, AC, and SCC samples. We selected

\section{Table 1: Clinic-pathological characteristics of patients with premalignant lung lesions and IL-27R $\alpha$ expression profiles of these lesions}

\begin{tabular}{|c|c|c|c|c|}
\hline \multirow{2}{*}{ Variables } & & \multicolumn{3}{|c|}{ IL-27R $\alpha$ immunostaining* } \\
\hline & & \multirow[t]{2}{*}{ Positive } & \multirow[t]{2}{*}{ Weakly Positive } & \multirow[t]{2}{*}{ Negative } \\
\hline Age: (range 50-78) & & & & \\
\hline \multicolumn{5}{|l|}{ Gender } \\
\hline Male & 14 & 10 & 3 & - \\
\hline Female & 6 & 5 & 1 & - \\
\hline \multicolumn{5}{|l|}{ Histological type } \\
\hline AAH & 7 & 7 & - & - \\
\hline $\begin{array}{l}\text { SM and Dysplasia (mild, } \\
\text { moderate, severe) }\end{array}$ & 7 & 4 & 2 & - \\
\hline SCIS & 6 & 4 & 2 & - \\
\hline
\end{tabular}

${ }^{*}$ IL-27R $\alpha$ immunostaining was scored as negative, positive or weakly positive as described in Methods. 
Table 2: Clinic-pathological characteristics of patients with lung cancer and IL-27R $\alpha$ expression profiles of these cancers

\begin{tabular}{|c|c|c|c|c|}
\hline \multirow{2}{*}{ Variables } & & \multicolumn{3}{|c|}{ IL-27R $\alpha$ immunostaining of the primary tumor* } \\
\hline & & \multirow[t]{2}{*}{ Positive } & \multirow[t]{2}{*}{ Weakly positive } & \multirow[t]{2}{*}{ Negative } \\
\hline \multicolumn{2}{|c|}{ Age (range 38-79) } & & & \\
\hline \multicolumn{5}{|l|}{ Gender } \\
\hline Male & 45 & $13(29 \%)$ & $26(58 \%)$ & $6(13 \%)$ \\
\hline Female & 13 & $7(54 \%)$ & $5(38 \%)$ & $1(8 \%)$ \\
\hline \multicolumn{5}{|c|}{ Histological type } \\
\hline$N S C L C$ & 58 & $20(34 \%)$ & $31(54 \%)$ & $7(12 \%)$ \\
\hline $\mathrm{AC}$ & 33 & $15(45 \%)$ & $15(45 \%)$ & $3(10 \%)$ \\
\hline SCC & 25 & $5(20 \%)$ & $16(64 \%)$ & $4(16 \%)$ \\
\hline \multicolumn{5}{|l|}{ Tumor size } \\
\hline $\mathrm{T} 1$ & 29 & $8(28 \%)$ & $16(55 \%)$ & $5(17 \%)$ \\
\hline $\mathrm{T} 2$ & 27 & $12(45 \%)$ & $13(48 \%)$ & $2(7 \%)$ \\
\hline $\mathrm{T} 3$ & 2 & $2(100 \%)$ & - & - \\
\hline \multicolumn{5}{|c|}{ Lymph node status } \\
\hline N0 & 34 & $6(18 \%)$ & $21(62 \%)$ & $7(20 \%)$ \\
\hline N1 & 24 & $14(58 \%)$ & $10(42 \%)$ & - \\
\hline $\mathrm{N} 2$ & - & - & - & - \\
\hline \multicolumn{5}{|l|}{ Stage } \\
\hline IA & 16 & $2(13 \%)$ & $9(56 \%)$ & $5(31 \%)$ \\
\hline IB & 18 & $4(22 \%)$ & $12(67 \%)$ & $2(11 \%)$ \\
\hline IIA & 13 & $8(62 \%)$ & $5(38 \%)$ & - \\
\hline IIB & 9 & $4(44 \%)$ & $5(56 \%)$ & - \\
\hline IIIA & 2 & $2(100 \%)$ & - & - \\
\hline \multicolumn{5}{|c|}{ Smoking history } \\
\hline Smokers & 42 & $16(38 \%)$ & $20(48 \%)$ & $6(14 \%)$ \\
\hline Non smokers & 16 & $4(25 \%)$ & $11(69 \%)$ & $1(6 \%)$ \\
\hline
\end{tabular}

*IL-27R $\alpha$ immunostaining was scored as negative, positive or weakly positive as described in Methods.

the bronchial epithelium from normal lung sections and tumor cells from AC or SCC sections. Details are provided in the Supplementary information.

\section{Mouse studies}

Four- to six-week-old athymic-nude and SCID/ NOD mice (Harlan Laboratories, Udine, Italy) were housed under specific pathogen-free conditions. Details on Tumor growth experiments in mice pre-treated or not with the myeloablative agent treosulfan (Medac) [50], and schedule of hrIL-27 administration are provided in the Supplementary information.

\section{Histopathological and morphometric analyses}

Methods for histology, immunohistochemistry, TUNEL assay, and the list of Abs used are reported in the Supplementary information.

IL-27R $\alpha$ expression by pre-neoplastic and neoplastic lesions was defined as positive, weakly positive, or negative. Details on the evaluation of IL-27R $\alpha$ expression, in human samples, and of Nestin, E-Cadherin, and cytokine expression; counts of microvessels, and immune cells, percentage of apoptotic cells, and cancer cells expressing stemness or EMT-related genes, in tumor xenografts, are reported in the Supplementary information. 
Table 3: Immunohistochemical analyses of tumors developed after subcutaneous injection of Calu-6 or SK-MES cells in SCID/NOD and athymic NU/NU Mice, respectively, and treated with PBS or hrIL-27

\begin{tabular}{|c|c|c|c|c|c|c|c|c|c|c|c|c|}
\hline & \multicolumn{6}{|c|}{ Calu-6 } & \multicolumn{6}{|c|}{ SK-MES } \\
\hline & \multicolumn{3}{|c|}{ PBS } & \multicolumn{3}{|c|}{ hrIL-27 } & \multicolumn{3}{|c|}{ PBS } & \multicolumn{3}{|c|}{ hrIL-27 } \\
\hline Immune Cells & & & & & & & & & & & & \\
\hline Granulocytes & 7.0 & \pm & 3.3 & 25.0 & \pm & $7.2^{\dagger}$ & 14.5 & \pm & 5.6 & 31.4 & \pm & $6.0^{\dagger}$ \\
\hline Macrophages & 8.5 & \pm & 4.1 & 21.4 & \pm & $6.3^{\dagger}$ & 12.0 & \pm & 4.2 & 27.0 & \pm & $6.5^{\dagger}$ \\
\hline Blood Vessels & 9.8 & \pm & 4.0 & 7.7 & \pm & 3.0 & 12.8 & \pm & 4.9 & 5.0 & \pm & $2.2^{\dagger}$ \\
\hline $\begin{array}{l}\text { Apoptotic } \\
\text { Index }\end{array}$ & 2.5 & \pm & $2.0 \%$ & 8.9 & \pm & $3.2 \%^{\dagger}$ & 3.4 & \pm & $2.2 \%$ & 10.5 & \pm & $3.5 \%$ \\
\hline \multicolumn{13}{|l|}{$\begin{array}{l}\text { Human } \\
\text { Cytokines* }\end{array}$} \\
\hline CXCL3 & & \pm & & & ++ & & & \pm & & & ++ & \\
\hline IFN $\gamma$ & & - & & & - & & & - & & & + & \\
\hline $\mathrm{TNF} \alpha$ & & - & & & + & & & \pm & & & ++ & \\
\hline Nestin* & & ND & & & ND & & & ++ & & & \pm & \\
\hline E-Cadherin* & & ND & & & ND & & & + & & & ++ & \\
\hline \multicolumn{13}{|l|}{$\begin{array}{l}\text { Stemness } \\
\text { genes }\end{array}$} \\
\hline $\mathrm{SHH}$ & 88.0 & \pm & $8.9 \%$ & 58.5 & \pm & $10.3 \%^{\dagger}$ & & & & & & \\
\hline OCT4A & & $\mathrm{ND}^{\ddagger}$ & & & ND & & 85.0 & \pm & $11.5 \%$ & 59.4 & \pm & $12.2 \%^{\dagger}$ \\
\hline SOX2 & & ND & & & ND & & 79.2 & \pm & $9.0 \%$ & 40.5 & \pm & $15.6 \%^{\dagger}$ \\
\hline SOX9 & & ND & & & ND & & 84.5 & \pm & $11.3 \%$ & 62.5 & \pm & $9.0 \% \%^{\dagger}$ \\
\hline NOTCH1 & & ND & & & ND & & 86.2 & \pm & $8.0 \%$ & 63.1 & \pm & $10.5 \%^{\dagger}$ \\
\hline KLF4 & & ND & & & ND & & 78.3 & \pm & $10.0 \%$ & 39.0 & \pm & $14.2 \%^{\dagger}$ \\
\hline \multicolumn{13}{|l|}{$\begin{array}{l}\text { EMT-related } \\
\text { genes }\end{array}$} \\
\hline SNAI1 & & ND & & & ND & & 85.3 & \pm & $9.0 \%$ & 66.4 & \pm & $8.0 \%^{\dagger}$ \\
\hline SNAI2 & & ND & & & ND & & 80.5 & \pm & $8.2 \%$ & 58.5 & \pm & $10.3 \%^{\dagger}$ \\
\hline ZEB1 & & ND & & & ND & & 71.8 & \pm & $10.0 \%$ & 49.7 & \pm & $9.2 \%^{\dagger}$ \\
\hline
\end{tabular}

Assessment of cytokine, Nestin and E-cadherin expression, and counts of microvessels, immune cells, TUNEL positive cells, stemness and EMT-related gene expressing cells were performed at X400 in a $0.180 \mathrm{~mm}^{2}$ field. At least 3 samples (three sections/sample), and 6-8 (depending on the tumor width) randomly chosen fields/section were evaluated. Results are expressed as mean $\pm \mathrm{SD}$ of CD31 positive microvessels per field; or RB6-8C5 (granulocytes) or CD11b/CD18 (macrophages) positive cells per field; or as mean \pm SD percentage of TUNEL positive cells, or stemness- or EMT-related gene expressing cells evaluated on paraffin embedded sections by immunohistochemistry. ${ }^{*}$ The expression of cytokines, Nestin and E-Cadherin was defined as absent $(-)$; scarce $( \pm)$; distinct $(+)$ or strong $(++)$ on paraffin embedded (CXCL3, IFN $\gamma$, Nestin and E-Cadherin) or frozen (TNF $\alpha$ ) sections stained with the corresponding Ab. †Values significantly different $(P<0.05)$ from corresponding values in tumors developed in PBS-treated mice. $\$ N D$, not detected.

\section{Statistical analysis}

Tumor volumes were reported in $\mathrm{mm}^{3}$ versus time. Differences in tumor volume, microvessel density and counts of immune cells or percentage of apoptotic cells or stemness and EMT-gene expressing cells between tumors from hrIL-27- and PBS-treated mice were assessed by Student's $t$ test, and data were reported as mean \pm standard deviation (SD). Between-group differences in the relative expression of IL-27R $\alpha$ mRNA, by real-time RT-PCR, were 
assessed by one-way analysis of variance (ANOVA) and the difference between each pair of means was evaluated with the Tukey's HSD test.

Fisher's exact test was used to examine the association between IL-27R $\alpha$ protein expression, evaluated by immunohistochemistry, in primary lung tumors, and clinic-pathological characteristics. The Spearman rank correlation coefficient $(\rho)$ was used to examine the correlation between immunohistochemical staining and real-time RT-PCR for IL-27R $\alpha$ expression. The SPSS software, version 11.0 (IBM, Armonk, NY, USA) was employed, with $P<0.05$ as the significance cut-off.

\section{Abbreviations}

AAH, Atypical Adenomatous Hyperplasia; AC, Adenocarcinoma; BMI1, Polycomb complex protein 1; $\mathrm{CDH}$, Cadherin; CXCL3, Chemokine (CXC motif) ligand 3; ECGF1, Platelet-Derived Endothelial Cell Growth Factor 1; EMT, Epithelial-Mesenchymal Transition; GRO $\gamma$, Growth Related Oncogene protein gamma; IFN $\gamma$, Interferon gamma; IL, Interleukin; KLF4, Krüppel-Like Factor 4; LCM, Laser Capture Microdissection; LLC1, Lewis Lung Carcinoma line 1; MIP2 $\beta$, Macrophage Inflammatory Protein 2 beta; mtv, mean tumor volume; NANOG, Nanog Homeobox; NOTCH1, Notch homolog 1; NSCLC, Non-Small Cell Lung Cancer; OCT4A, Octamer-Binding Transcription factor 4 A; R, Receptor; SCC, Squamous Cell Carcinoma; SCIS, squamous cell carcinoma in situ; SE, standard error; SHH, Sonic Hedgehog; SM, Squamous Metaplasia; SOX, SRY (sex determining region Y)-box; TYMP-1, Tissue Inhibitor of Metalloproteinase-1; TLS, Tertiary Lymphoid Structures; TNF, Tumor Necrosis Factor; TRAIL, TNFRelated Apoptosis Inducing Ligand; TUNEL, Terminal deoxynucleotidyl transferase dUTP nick end labeling; TWIST, twist family bHLH transcription factor; VE, Vascular Endothelial; ZEB, Zinc finger E-box binding homeobox.

\section{ACKNOWLEDGMENTS}

This work was supported by grants from the Associazione Italiana Ricerca sul Cancro (AIRC, Investigator Grant n. 13134) and the "Umberto Veronesi" Foundation for the Progress of Sciences to E. Di Carlo; and grants from AIRC (Investigator Grant n. 13018), Ricerca Finalizzata Collaboratore Estero, Ministero della Salute (Grant n. RF-2010-2308270), and from Cinque per mille e Ricerca Corrente, Ministero della Salute to I. Airoldi.

\section{Author contributions}

EDC planned and designed experiments, collected data and wrote the manuscript; IA designed and performed experiments; MGT, SE, MVR, and GB, performed experiments and collected data; GC provided tissue samples and clinic-pathological data.

\section{Conflicts of interest}

The authors disclose no potential conflicts of interest.

\section{REFERENCES}

1. Jemal A, Bray F, Center MM, Ferlay J, Ward E, Forman D. Global cancer statistics. CA Cancer J Clin. 2011; 61:69-90.

2. Ferlay J, Soerjomataram I, Ervik M, Dikshit R, Eser S, Mathers C, Rebelo M, Parkin DM, Forman D, Bray F. GLOBOCAN 2012 v1.0, Cancer Incidence and Mortality Worldwide: IARC CancerBase No. 11 [Internet]. Lyon, France: International Agency for Research on Cancer 2013; Available from http://globocan.iarc.fr.

3. Lortet-Tieulent J, Soerjomataram I, Ferlay J, Rutherford M, Weiderpass E, Bray F. International trends in lung cancer incidence by histological subtype: adenocarcinoma stabilizing in men but still increasing in women. Lung Cancer. 2014; 84:13-22.

4. Majem M, Pallarès C. An update on molecularly targeted therapies in second- and third-line treatment in non-small cell lung cancer: focus on EGFR inhibitors and antiangiogenic agents. Clin Transl Oncol. 2013; 15:343-357.

5. Cardarella S, Johnson BE. The impact of genomic changes on treatment of lung cancer. Am J Respir Crit Care Med. 2013; 188:770-775.

6. Vignali DA, Kuchroo VK. IL-12 family cytokines: immunological playmakers. Nat Immunol. 2012; 13:722-728.

7. Bosmann M, Ward PA. Modulation of inflammation by interleukin-27. J Leukoc Biol. 2013; 94:1159-1165.

8. Zorzoli A, Di Carlo E, Cocco C, Ognio E, Ribatti D, Ferretti E, Dufour C, Locatelli F, Montagna D, Airoldi I. Interleukin-27 inhibits the growth of pediatric acute myeloid leukemia in NOD/SCID/I12rg-/- mice. Clin Cancer Res. 2012; 18:1630-1640.

9. Murugaiyan G, Saha B. IL-27 in tumor immunity and immunotherapy. Trends Mol Med. 2013; 19:108-116.

10. Di Carlo E, Sorrentino C, Zorzoli A, Di Meo S, Tupone MG, Ognio E, Mincione G, Airoldi I. The antitumor potential of Interleukin-27 in prostate cancer. Oncotarget. 2014; 5:10332-10341.

11. Ho MY, Leu SJ, Sun GH, Tao MH, Tang SJ, Sun KH. IL27 directly restrains lung tumorigenicity by suppressing cyclooxygenase-2-mediated activities. J Immunol. 2009; 183:6217-6226.

12. Kachroo P, Lee MH, Zhang L, Baratelli F, Lee G, Srivastava MK, Wang G, Walser TC, Krysan K, Sharma S, Dubinett SM, Lee JM. IL-27 inhibits epithelialmesenchymal transition and angiogenic factor production in a STAT1-dominant pathway in human non-small cell lung cancer. J Exp Clin Cancer Res. 2013; 32:97. 
13. Zhang J, Tian H, Li C, Cheng L, Zhang S, Zhang X, Wang R, Xu F, Dai L, Shi G, Chen X, Li Y, Du T, et al. Antitumor effects obtained by autologous Lewis lung cancer cell vaccine engineered to secrete mouse interleukin 27 by means of cationic liposome. Mol Immunol. 2013; 55:264-274.

14. Strieter RM, Polverini PJ, Kunkel SL, Arenberg DA, Burdick MD, Kasper J, Dzuiba J, Van Damme J, Walz A, Marriott D, Chan SY, Roczniak S, Shanafelt AB. The functional role of the ELR motif in CXC chemokine-mediated angiogenesis. J Biol Chem. 1995; 270:27348-27357.

15. Geiser T, Dewald B, Ehrengruber MU, Clark-Lewis I, Baggiolini M. The interleukin-8-related chemotactic cytokines GRO alpha, GRO beta, and GRO gamma activate human neutrophil and basophil leukocytes. J Biol Chem. 1993; 268:15419-15424.

16. Baggiolini M, Dewald B, Moser B. Interleukin- 8 and related chemotactic cytokines - $\mathrm{CXC}$ and $\mathrm{CC}$ chemokines. Adv Immunol. 1994; 55:97-179.

17. Koch AE, Kunkel SL, Harlow LA, Mazarakis DD, Haines GK, Burdick MD, Pope RM, Strieter RM. Macrophage inflammatory protein-1 alpha. A novel chemotactic cytokine for macrophages in rheumatoid arthritis. J Clin Invest. 1994; 93:921-928.

18. Wiese C, Rolletschek A, Kania G, Blyszczuk P, Tarasov KV, Tarasova Y, Wersto RP, Boheler KR, Wobus AM. Nestin expression - a property of multi-lineage progenitor cells? Cell Mol Life Sci. 2004; 61:2510-2522.

19. Narita K, Matsuda Y, Seike M, Naito Z, Gemma A, Ishiwata $\mathrm{T}$. Nestin regulates proliferation, migration, invasion and stemness of lung adenocarcinoma. Int $\mathrm{J}$ Oncol. 2014; 44:1118-1130.

20. Kalluri R, Weinberg RA. The basics of epithelialmesenchymal transition. J Clin Invest. 2009; 119:1420-1428.

21. Sánchez-Tilló E, Liu Y, de Barrios O, Siles L, Fanlo L, Cuatrecasas M, Darling DS, Dean DC, Castells A, Postigo A. EMT-activating transcription factors in cancer: beyond EMT and tumor invasiveness. Cell Mol Life Sci. 2012; 69:3429-3456.

22. Grotegut S, von Schweinitz D, Christofori G, Lehembre F. Hepatocyte growth factor induces cell scattering through MAPK/Egr-1-mediated upregulation of Snail. EMBO J. 2006; 25:3534-3545.

23. Leroy P, Mostov KE. Slug is required for cell survival during partial epithelial-mesenchymal transition of HGFinduced tubulogenesis. Mol Biol Cell. 2007; 18:1943-1952.

24. Xu S, Neamati N. gp130: a promising drug target for cancer therapy. Expert Opin Ther Targets. 2013; 17:1303-1328.

25. Haura EB, Livingston S, Coppola D. Autocrine interleukin-6/interleukin-6 receptor stimulation in non-small-cell lung cancer. Clin Lung Cancer. 2006; 7:273-275.

26. Dieu-Nosjean MC, Antoine M, Danel C, Heudes D, Wislez M, Poulot V, Rabbe N, Laurans L, Tartour E, de Chaisemartin L, Lebecque S, Fridman WH, Cadranel J.
Long-term survival for patients with non-small-cell lung cancer with intratumoral lymphoid structures. J Clin Oncol. 2008; 26:4410-4417.

27. Sautès-Fridman C, Cherfils-Vicini J, Damotte D, Fisson S, Fridman WH, Cremer I, Dieu-Nosjean MC. Tumor microenvironment is multifaceted. Cancer Metastasis Rev. 2011; 30:13-25.

28. McCarthy F, Roshani R, Steele J, Hagemann T. Current clinical immunotherapy targets in advanced nonsmall cell lung cancer (NSCLC). J Leukoc Biol. 2013; 94:1201-1206.

29. Chambers SE, O’Neill CL, O’Doherty TM, Medina RJ, Stitt AW. The role of immune-related myeloid cells in angiogenesis. Immunobiology. 2013; 218:1370-1375.

30. Galdiero MR, Bonavita E, Barajon I, Garlanda C, Mantovani A, Jaillon S. Tumor associated macrophages and neutrophils in cancer. Immunobiology. 2013; 218:1402-1410.

31. Tecchio C, Scapini P, Pizzolo G, Cassatella MA. On the cytokines produced by human neutrophils in tumors. Semin Cancer Biol. 2013; 23:159-170.

32. Di Carlo E, Forni G, Lollini P, Colombo MP, Modesti A, Musiani $\mathrm{P}$. The intriguing role of polymorphonuclear neutrophils in antitumor reactions. Blood. 2001; 97:339-345.

33. de Fraipont F, Nicholson AC, Feige JJ, Van Meir EG. Thrombospondins and tumor angiogenesis. Trends Mol Med. 2001; 7:401-407.

34. Dejana E, Vestweber D. The role of VE-cadherin in vascular morphogenesis and permeability control. Prog Mol Biol Transl Sci. 2013; 116:119-144.

35. Ishikawa F, Miyazono $\mathrm{K}$, Hellman U, Drexler $\mathrm{H}$, Wernstedt C, Hagiwara K, Usuki K, Takaku F, Risau W, Heldin $\mathrm{CH}$. Identification of angiogenic activity and the cloning and expression of platelet-derived endothelial cell growth factor. Nature. 1989; 338:557-562.

36. Wirtz S, Tubbe I, Galle PR, Schild HJ, Birkenbach M, Blumberg RS, Neurath MF. Protection from lethal septic peritonitis by neutralizing the biological function of interleukin 27. J Exp Med. 2006; 203:1875-1881.

37. Pflanz S, Hibbert L, Mattson J, Rosales R, Vaisberg E, Bazan JF, Phillips JH, McClanahan TK, de Waal Malefyt R, Kastelein RA. WSX-1 and glycoprotein 130 constitute a signal-transducing receptor for IL-27. J Immunol. 2004; 172:2225-2231.

38. Rinchai D, Khaenam $\mathrm{P}$, Kewcharoenwong $\mathrm{C}$, Buddhisa S, Pankla R, Chaussabel D, Bancroft GJ, Lertmemongkolchai G. Production of interleukin-27 by human neutrophils regulates their function during bacterial infection. Eur J Immunol. 2012; 42:3280-3290.

39. Radisky DC, LaBarge MA. Epithelial-mesenchymal transition and the stem cell phenotype. Cell Stem Cell. 2008; 2:511-512.

40. Pece S, Tosoni D, Confalonieri S, Mazzarol G, Vecchi M, Ronzoni S, Bernard L, Viale G, Pelicci PG, Di Fiore PP. 
Biological and molecular heterogeneity of breast cancers correlates with their cancer stem cell content. Cell. 2010; 140:62-73.

41. Hayashida T, Jinno H, Kitagawa Y, Kitajima M. Cooperation of cancer stem cell properties and epithelial-mesenchymal transition in the establishment of breast cancer metastasis. J Oncol. 2011;2011:591427. doi: 10.1155/2011/591427.

42. Chambers I, Tomlinson SR. The transcriptional foundation of pluripotency. Development. 2009; 136:2311-2322.

43. Merchant AA, Matsui W. Targeting Hedgehog - a cancer stem cell pathway. Clin Cancer Res. 2010; 16:3130-3140.

44. Ben-David U, Benvenisty N. The tumorigenicity of human embryonic and induced pluripotent stem cells. Nat Rev Cancer. 2011; 11:268-277.

45. Dibra D, Cutrera J, Xia X, Li S. WSX1 expression in tumors induces immune tolerance via suppression of effector immune cells. PLoS One. 2011; 6:e19072.
46. Sobin LH, Gospodarowicz MK, Wittekind CH. TNM classification of malignant tumors, 7th edition. 2009; Hoboken, NJ: Wiley-Blackwell. ISBN: 978-1-4443-3241-4.

47. Kerr KM. Pulmonary preinvasive neoplasia. J Clin Pathol. 2001; 54:257-271.

48. Wistuba II, Gazdar AF. Lung cancer preneoplasia. Annu Rev Pathol. 2006; 1:331-348.

49. Travis WD, Brambilla E, Müller-Hermelink HK, Harris CC. Pathology and genetics of tumours of the lung, pleura, thymus and heart, 3rd ed. World Health Organization international classification of tumors. 2004; Geneva: WHO Press.

50. Sjöö F, Hassan Z, Abedi-Valugerdi M, Griskevicius L, Nilsson C, Remberger M, Aschan J, Concha H, Gaughan U, Hassan M. Myeloablative and immunosuppressive properties of treosulfan in mice. Exp Hematol. 2006; 34:115-121. 